\title{
Benchmarking Projects: How to Apply It on Non-Industrial Projects
}

\author{
Elias Ikpe (Corresponding author) \\ Ph.D, Civil Engineering, University of Calgary, Alberta, Canada \\ E-mail: eliasikpe@yahoo.com \\ Jatinder Kumar \\ MSc. P.Eng., University of Calgary, Alberta, Canada
}

George Jergeas

Ph.D, P.Eng., Civil Engineering, University of Calgary, Alberta, Canada

Received: March 26, 2015 Accepted: April 20, 2015 Published: May 28, 2015

doi:10.5296/bmh.v3i1.7704 URL: http://dx.doi.org/10.5296/bmh.v3i1.7704

\begin{abstract}
This case study is an example to demonstrate the application and potential strength of benchmarking and its application on non-industrial projects. The paper provides a review of the benchmarking system, benchmarking process, benefit of benchmarking, benchmarking types and barrier of benchmarking. It also describes the use of benchmarking in different knowledge areas. The research shows example of planned contingency and schedule growth results from oil and gas projects executed in Alberta phases 1 \& 2 in CII/COAA database. The CII/COAA benchmarking approach was used to improve performance in projects executed in Alberta. The use of the benchmarking system can contribute to a better project performance on non-industrial projects. It is concluded that this approach can be used to benchmark other kinds of projects on non-industrial projects.
\end{abstract}

Keywords: benchmarking, application, non-industrial, projects, improvement 


\section{Introduction}

This case study is an example to demonstrate the application and the potential strength, and application of benchmarking approach on non-industrial projects. The paper reviews the application of CII/COAA benchmarking approach, process of benchmarking, type of benchmarking, and barriers to benchmarking, advantages of benchmarking, data miner, shows example of planned contingency and schedule analysis in Alberta phases 1 \& 2 projects and how to use benchmarking on non- industrial projects. It further discusses when and where to use benchmarking in the project life cycle. The use of benchmarking system can guide an individual organization or company on the best way to improve performance.In Alberta, oil and gas companies are using benchmarking as a primary tool to improve project performance. It is recognized as a core component of continuous improvement programs in the capital projects industry in Alberta. It assists estimators, project managers, and senior managers embarking on large oil and gas construction projects to deliver projects on budget and on time.

\section{Background}

Benchmarking is defined as the continuous and systematic process of measuring one's own performance against the results of recognized leaders for the purpose of finding best practices that lead to superior performance when implemented (Nasiretal, 2008). It is a measurement that can be used as a point of reference for comparative purposes to other organizations and is a continuous performance improvement tools (Alstete, 2008). It is regarded as one of the simplest tools for effective performance improvements (Williams et al., 2012). In the capital projects industry, benchmarking is primarily used at the project level to help participants identify gaps in their work processes, which lead to compromise performance (Brunso, 2003). For a given company, benchmarking provides sets of external comparisons to its peer group that can be used to establish improvement goals and objectively understand what "best in class” performance means (Mohammed, 1996). Typically, benchmarking looks at output (results) of a project resulting in lag benchmarks (Anderson \& McAdam, 2004).

Benchmarking can be a positive, proactive process to change operations in a structured fashion to achieve superior performance (Goncharuk \& Monat, 2009). According to Mohammed (1996) benchmarking will be successful if consistent methods of measuring performance are developed and used. However, benchmarking faces many challenges include incomplete or non-existent data. Reluctance to benchmarking impedes growth, knowledge transfer, cost effective solutions and use of knowledge to improve process performance (William et al., 2012). The benchmarking therefore represents a process of improving organizational practices where the focus is not simply copying others but to learn how to improve the organizational processes by the idea sharing (Watson, 1993) (as cited in Moriarity \& Smallman, 2009). The benchmarking is a powerful process impacting behaviour modification and developing new ways of business management and can be applied on non-industrial projects. 


\section{Macrothink}

Business and Management Horizons

ISSN 2326-0297

2015, Vol. 3, No. 1

\section{Types of Benchmarking}

The benchmarking can be regarded as a learning tool. Zairi (1994b) classified the benchmarking into 4 types (as cited in Moriarity \& Smallman, 2009)

1. Internal benchmarking: The objective is to determine the overall internal performance standard of an organization and can only be used to compare different departments in an organization and not external competition. This type of benchmarking can also be applied to government sector organisation where a systematic comparison of best practices can be made.

2. External benchmarking: This is competitive benchmarking. The goal is to compare an organization to its competitor in the same industry (e.g., COAA database). It helps organization to understand where it is standing in regards to performance.

3. Functional benchmarking: This type of benchmarking study is undertaken if non-competitor organization exhibits some excellence in certain areas of the business such as use of IT, admin Procedures, logistic processes. This benchmarking approach allows co-operation between the organisations because there is no risk of competition among them.

4. Generic benchmarking: It focuses on the best work but is costly and difficult to implement. This type of benchmarking improves the efficiency of the processes in a generic manner with a minimal sense of competitiveness. The comparison is conducted regardless of the location or type of industry.

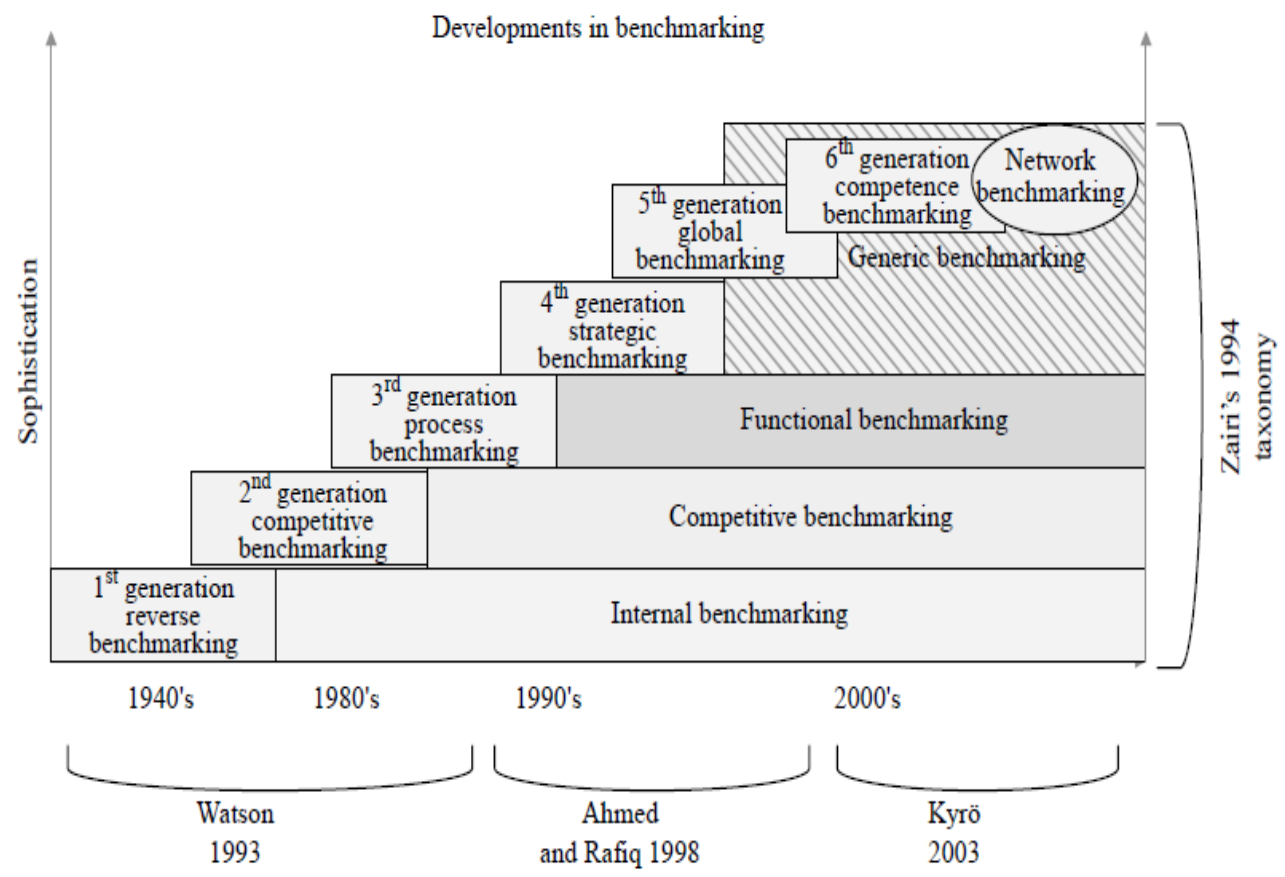

Sources: Adapted from Watson (1993): Ahmed and Rafia (1998): Kvrö (2003)

Figure 1. The development of these types of benchmarking with the passage of time Source: Adopted from Moriarity and Smallman (2009). 


\section{Macrothink}

The best way for an organization to find the suitable benchmarking type as shown in Figure 1 above is to determine whether they want to focus on financial results or meet the expectation of customers. Adopting and implementing the right practices is essential to attaining world-class performance (Saunders, 2008).

\subsection{Benchmarking Process}

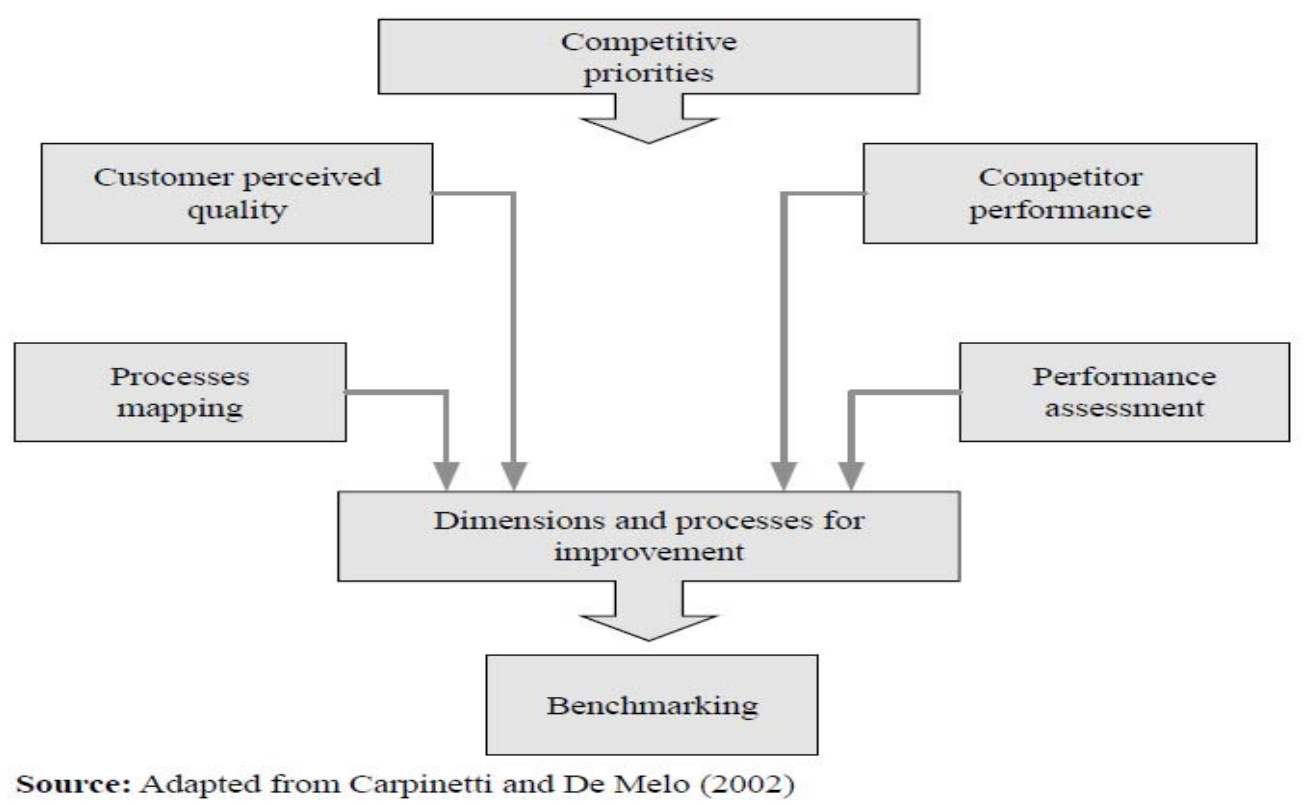

Figure 2. Flowchart of actual benchmarking process (Moriarty \& Smallman, 2009)

Benchmarking can be regarded as a sequence of activities involving process and assessment (Moriarity \& Smallman, 2009) as shown in Figure 2. This process are planning the exercise, forming the team, data collection, analyse data to identify possible gaps, take actions to improve your performance.

The process helps organization to understand their operations better and sets goal for improvement. Any organization that wants to improve its performance should follow this process. The only way to truly and objectively know whether or not project execution is improving is through continuous measurement (Jergeas, 2008).

\subsection{Benefits of Benchmarking}

The benefits of adopting benchmarking approach are numerous. Some examples are; increasing productivity, generating more revenue, saving cost, improving processes and being more creative, helping organization to understand what could be doing better, helping to identify room for growth organization are unaware of, helping organization to know where they stand in relation to others, helping organization in budgeting and planning. 


\subsection{Barriers of Benchmarking}

Adebanjo et al. (2010) identified some reasons why organizations are not adopting benchmarking as lack of resources, lack of benchmarking partners, lack of knowledge to plan benchmarking project, lack of top management support, and lack of understanding of benchmarking. In addition, labor shortage and incomplete data collection can be a major barrier of benchmarking. Collecting detailed precise data is vital to the consistency and reliability of the benchmarking process. These reasons can prevent companies and organizations from participating in an accurate and reliable benchmarking process. Davies \& Kochar (1999); Adebanjo et al. (2010) suggested that in order to eliminate these barriers to adoption and growth of benchmarking, education and awareness of top management, training and benchmarking skills development are keys to promote benchmarking across all areas of an organization. However, benchmarking needs top management support and employee participation, education and training to succeed (Lee, 2006).

\section{Research Method}

Qualitative approach was used to guide this article. Lincoln and Guba (1985) described the qualitative research approach as an enquiry process of comprehending a social or human problem /phenomenon based on building a complex holistic picture formed with words, reporting detailed views of informants and conducted in a natural setting. Walker (1997) and Creswell (2003) further described qualitative methodology as explanatory in nature with the principal aim of trying to unearth answers to how? and why? questions.

Table 1. Strategies associated with qualitative approach

\begin{tabular}{|c|c|c|c|c|}
\hline Enography & Grounded theory & Case study & Phenomenological & Narrative \\
\hline $\begin{array}{l}\text { The researcher } \\
\text { studies an intact } \\
\text { cultural group in a } \\
\text { natural setting over } \\
\text { prolong period of } \\
\text { time by collecting, } \\
\text { primarily } \\
\text { observational data }\end{array}$ & $\begin{array}{l}\text { The researcher } \\
\text { attempts to derive } \\
\text { a theory of a } \\
\text { process, action } \\
\text { behaviour or } \\
\text { interaction } \\
\text { grounded views of } \\
\text { participants in the } \\
\text { study; } \\
\text { It focuses attention } \\
\text { upon the way in } \\
\text { which scientific } \\
\text { work, which is } \\
\text { necessarily } \\
\text { concerned with } \\
\text { issues of discovery } \\
\text { or generatively. }\end{array}$ & $\begin{array}{l}\text { The researcher } \\
\text { intends to support } \\
\text { his or her argument } \\
\text { by an in-depth } \\
\text { analysis of a } \\
\text { person, a group of } \\
\text { persons, an } \\
\text { organisation or a } \\
\text { particular project. } \\
\text { The nature of the } \\
\text { case study focuses } \\
\text { on one aspect of a } \\
\text { problem, the } \\
\text { conclusion drawn } \\
\text { will not be } \\
\text { generalised but, } \\
\text { rather, related to } \\
\text { one particular } \\
\text { event. }\end{array}$ & $\begin{array}{l}\text { The investigator } \\
\text { identifies the "essence" } \\
\text { of human experiences } \\
\text { concerning a } \\
\text { phenomenon as } \\
\text { described by } \\
\text { participants in a study. } \\
\text { The researcher } \\
\text { 'brackets' his or her } \\
\text { experiences in order to } \\
\text { understand those of the } \\
\text { participants in the study }\end{array}$ & $\begin{array}{l}\text { Form of enquiry } \\
\text { in which the } \\
\text { researcher } \\
\text { studies the lives } \\
\text { of individuals } \\
\text { and asks one or } \\
\text { more individuals } \\
\text { to provide stories } \\
\text { about their lives. } \\
\text { Narrative } \\
\text { analysis is } \\
\text { subjective and it } \\
\text { does not give } \\
\text { adequate } \\
\text { coverage in all } \\
\text { lines of work. }\end{array}$ \\
\hline
\end{tabular}

Source: Rooke (1995); Rooke et al. (1997); Creswell (2003). 
The qualitative approach is associated with strategies such as phenomenological, case studies, ethnographies, narratives and grounded theory (Creswell, 2003). The strategies associated with qualitative approach are summarised in Table 1 above. A number of authors (e.g., Seymour and Rooke (1995) and Rooke et al. (1997) have advocated for the use of these strategies in construction management research.

For the purpose of this research, the authors consider case study approach of the qualitative method as more suitable to understand the benchmarking system. Patton (1990) described case studies as particularly useful in depicting a holistic portrayal of a client's experiences and results regarding a program. It is the preferred strategy when 'how', 'who',' why' or 'what' questions are being asked. In a case study, the focus of attention is on the case in its idiosyncratic complexity, not on the whole population of cases (Burns, 2000).

\section{Use of Benchmarking in Different Knowledge Areas}

The term benchmarking is used in wide range of human efforts. It is essential to any organizational improvement process where current state of affairs is considered undesirable (due to ineffectiveness or inefficiency) until replaced by more desirable state of affairs based on evidence or an understanding that such states can be improved (Chen, 2005; Dawkins et al., 2007). It was applied in double loop organisational learning by (Argyris, 1977), in knowledge management initiatives by (McAdam \& McCreedy, 1999), in total quality management by (Franceschini et al., 2006), supply chain management (Deming, 1982), Six Sigma (Xerox, 1979), performance measurement (Anderson \& McAdam, 2004; Alstete, 2008) (as cited in Moriarity \& Smallman, 2009) and used in construction by CII, oil and gas industry by COAA. Benchmarking can be extensively used in organisational and manufacturing processes.

\subsection{Benchmarking in Construction}

Many institutions are involved in research related to measure the performance of the construction projects in order to improve the performance. Construction Industry Institute (CII) of United States, Building Research Establishment Ltd. (BRE) UK, European Construction Industry Institute (ECI) and Construction Owners Association of Alberta (COAA) are some of them which have conducted extensive research on benchmarking and have produced many publications related to developing benchmarking tools and metrics to evaluate and measure the success or performance of the construction projects (Jergeas, 2009). Performance measurement is a very important part of the construction management, because all companies expecting continuous performance improvement and desire to maximize their profits in the long run. But measuring the performance is just not enough and it needed to be compared with the known standards or to other competitive construction projects (BRE, 2011). 


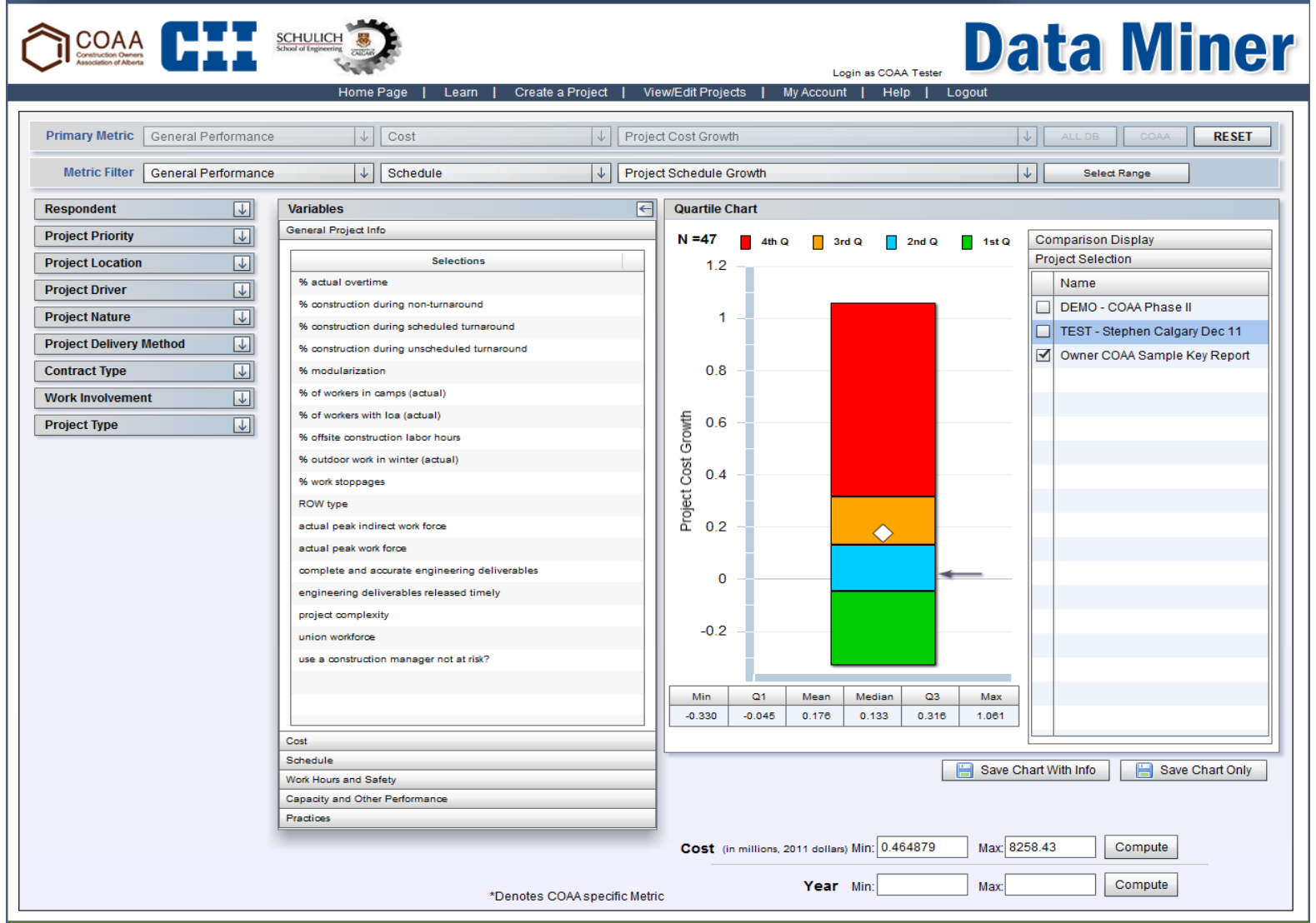

Figure 3. Data miner

Source: COAA (2009).

The COAA data miner, which can be seen in Figure 3 above, is a user-defined format. The user starts by selecting a primary metric of interest and a quartile chart appears in color. This chart includes all projects in the combined COAA and CII database containing the specific metric. Then, the user can begin a process of 'filtering' the comparison cohort. Aggregate data can be seen for any metric contributed by any COAA or CII member company.

\subsection{How Industry is Using COAA Benchmarking System}

Figure $4 \& 5$ below shows an example of benchmarking of research finding results for oil and gas projects executed in Alberta phases 1 \& 2 projects comparison. 
5.3.1 Planned Contingency/Total Project Cost

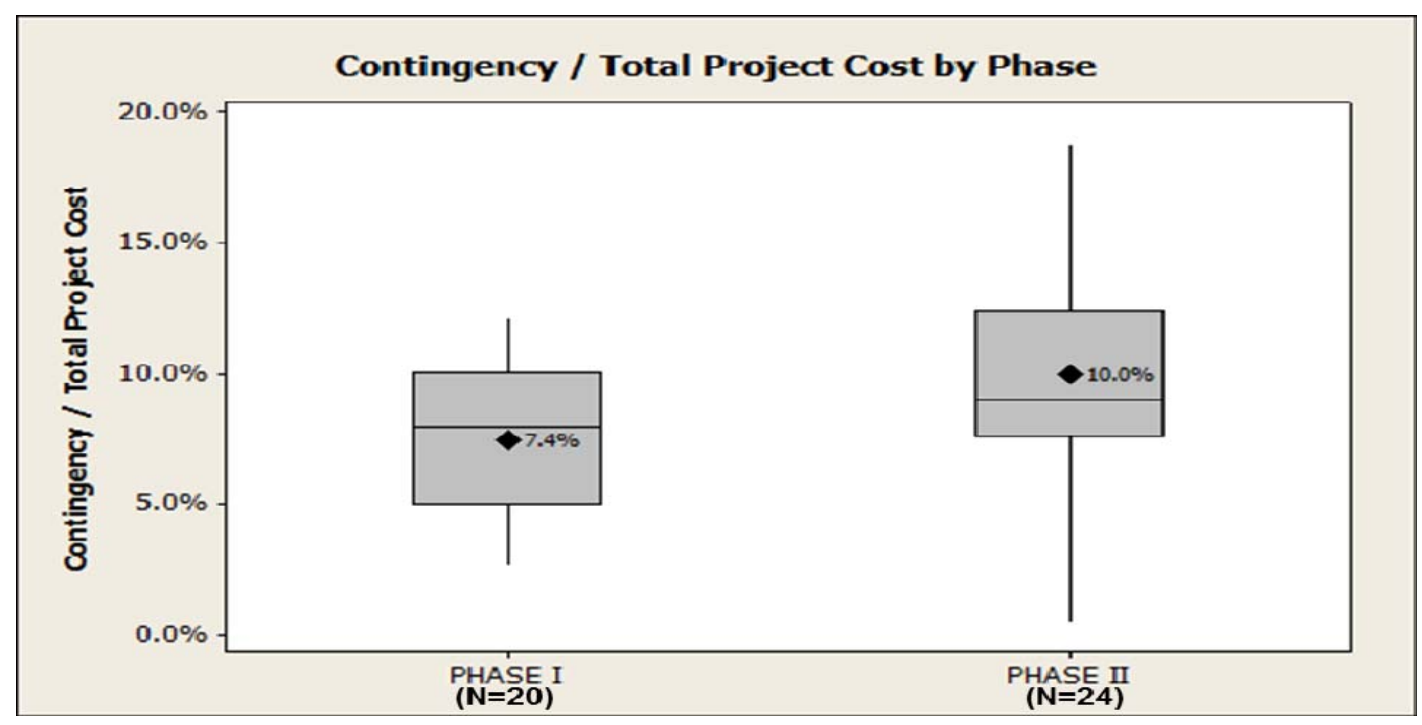

Figure 4. Planned contingency/total project cost phas1 \& phase 2

As can be seen in Figure 4, project data shows a slightly lower average contingency rate (7.4\%) for phase 1 when compared to phase 2 (10\%) for Alberta projects. In Alberta, on average contingency is $8-10 \%$ of total project cost. Phase 1 projects contingency varies from $2 \%$ to $13 \%$ while phase 2 projects contingency varies from $1 \%$ to $18 \%$. So phase 2 projects have wider variation than phase 1 projects.

\subsubsection{Project Schedule Growth}

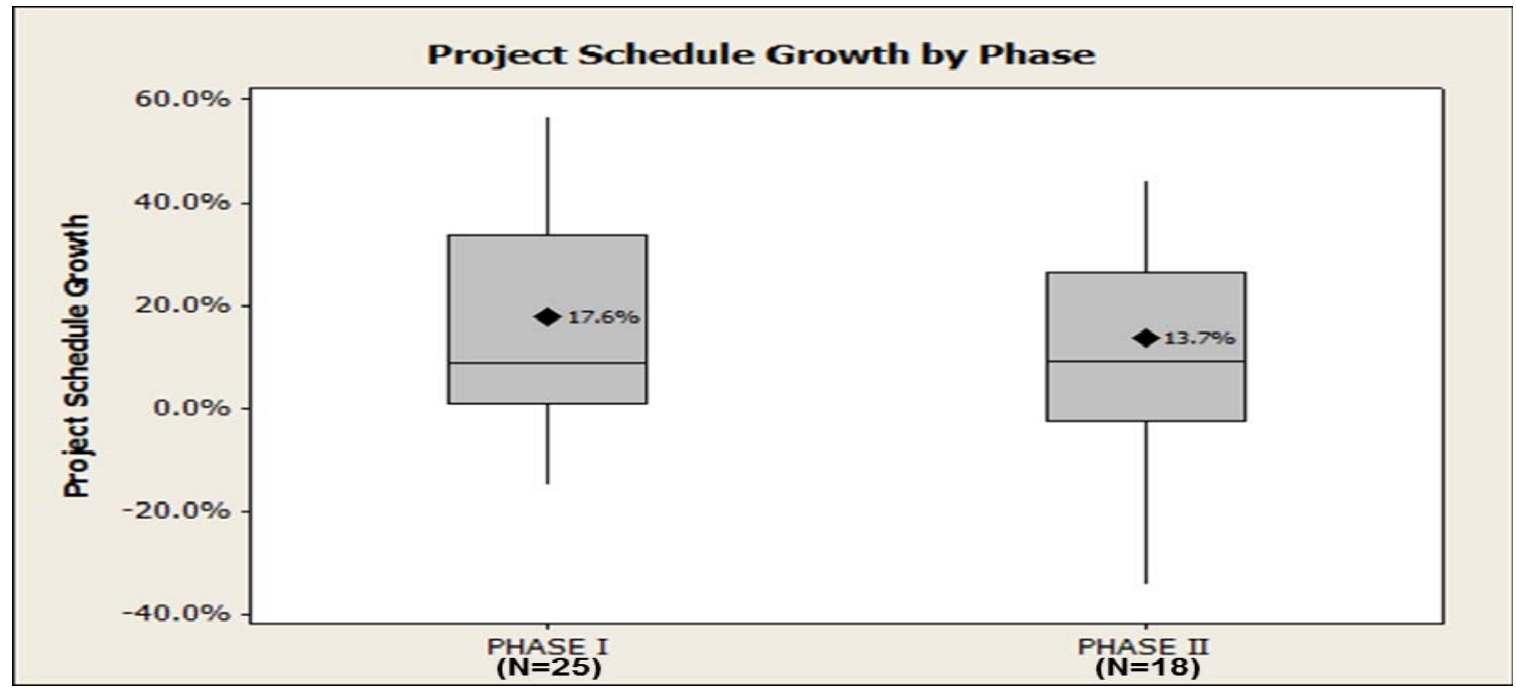

Figure 5. Project schedule growth

Figure 5 compares the project schedule growth in phases 1 \&2 of projects executed in Alberta. 
Results show higher average schedule performance for the Alberta projects in phase 1 than phase 2. On average, phase 1 projects experienced $17.6 \%$ project schedule growth, while phase 2 projects experienced $13.7 \%$ schedule growth, respectively. These projects also demonstrate that a much wider range of performance exists as well. Phase 1 projects schedule growth varies from $-15 \%$ to $55 \%$ while phase 2 projects schedule growth varies from $-35 \%$ to $40 \%$. So phase 1 projects have wider variation than phase 2 projects.

\section{Decision and Application of Benchmarking on Non- Industrial Projects}

This benchmarking approach can be used to other kinds of projects such as competitive and non-competitive organizations. It can be applied to business such as use of IT, admin procedures, logistic processes and to government sector organization where a systematic comparison of best practices can be made. Benchmarking is becoming a reliable tool and can be used to identify new ideas and new ways of improving process. It improves project and company performance when use as an ongoing process. The process is carried out through the entire project lifecycle with the support of organization members. One of the reasons for inconsistency in the benchmarking process is lack of organizational culture in regards to the accurate data collection. The actual data needs to be gathered over and over through the lifecycle of a project.

As shown in Figures 4 \& 5 above, despite Alberta capital projects that were compounded by extremes experienced in Alberta related to such things as labour availability, harsh weather conditions, and remote project locations, amongst others, benchmarking of oil and gas projects was done to measure performance of these capital projects executed in Alberta and compare both phases $1 \& 2$ projects. The project schedule growth in phases $1 \& 2$ of projects shows higher average schedule performance for the Alberta projects in phase 1 than phase 2 . The phase 1 projects experienced $17.6 \%$ project schedule growth, and phase 2 projects experienced $13.7 \%$ schedule growth, respectively on the average.

\section{Conclusion}

The case study is an example to demonstrate the application of benchmarking and potential strength and application on non-industrial projects. The benchmarking is a powerful process impacting behaviour modification and developing new ways of business management and can be applied on non-industrial projects. Benchmarking needs top management support and employee participation, education and training to succeed. It has been applied in double loop organisational learning, knowledge management initiatives total quality management, supply chain management, Six Sigma, performance measurement and construction oil and gas industry.

The case study shows some examples of how benchmarking was used in oil and gas projects in Alberta such as comparing the project phases 1 \& 2 contingency and schedule growth. Benchmarking has been recognized as a core component of continuous improvement programs in the capital projects industry in Alberta. Implementing specific benchmarking approaches on Alberta-based projects has provided the participating companies with a systematic process to measure project performance, enable external comparisons with peers' 
projects, and establish project objectives. The benchmarking approach can be used to other kinds of projects such as competitive and non-competitive organizations to improve performance.

\subsection{Recommendation}

Benchmarking can be a positive, proactive process to change operations in a structural faction to achieve superior performance. There is a need to set realistic targets and objectives, encourage commitment to long term findings, strong direction and management support, establish and communicate benchmarking definitions and guidelines and use education and training. In order to gather enough data for benchmarking, companies must have sufficient information in regards to their past completed projects. The depth of data collection needs to be identified based on the purpose of benchmarking, the intentions of management team, and the availability of resources for accurate data collection. The process needs dedicated crews from different teams and parties such as the project control department, the engineering department, and the management organization.. Removal of obstacles to benchmarking should be linked to competitive priorities, improvement programs and performance measurement. One of the huge barriers to accurate and truthful data collection is a lack of competent and capable data collectors.

\section{Acknowledgements}

The authors would like to thank Natural Sciences and Engineering Research Council of Canada (NSERC), Construction Owners Association of Alberta (COAA), Construction Industry Institute (CII) and COAA contributing members for providing financial support, data and guidance.

\section{References}

Adebanjo, D. (2010). An investigation of the adoption and implementation of benchmarking. International Journal of Operations \& Production Management, 30(11), 1140-1169. http://dx.doi.org/10.1108/01443571011087369

Alstete, J. (2008). Measurement benchmarks or 'real' benchmarking? An examination of current perspectives. Benchmarking: An International Journal, 15(2), 178-186. http://dx.doi.org/10.1108/14635770810864884

Anderson, K., \& McAdam, R. (2004). A critique of benchmarking and performance measurement: Lead or Lag? Benchmarking: An International Journal, 11(5), 465-483.

Brunso, T. P., \& Siddiqi, K. M. (2003). Using Benchmarks and Metrics to Evaluate Project Delivery of Environmental Restoration Programs. Journal of Construction Engineering and Management, 129(2), 119-130. http://dx.doi.org/10.1061/(ASCE)0733-9364(2003)129:2(119)

Building Research Establishment (BRE). (2011). Key performance indicators (KPI's) for the construction industry. [Online] Available: http://www.bre.co.uk/page.jsp?id=1478

Chen, H. L. (2005). A competence-based strategic management model factoring in key 
factors and benchmarking. Benchmarking: An International Journal, 12(4), 364-374. http://dx.doi.org/10.1108/14635770510609033

Creswell, J. W. (2003). Research Design: Qualitative, quantitative and Mixed Method Approaches. Thousand Oaks, California: Sage Publication.

Davies, A. J., \& Kochar, A. L. (1999). Why British companies don't do effective benchmarking. Integrated Manufacturing Systems, $\quad 10(1), \quad 26-32$. http://dx.doi.org/10.1108/09576069910247573

Dawkins, P., Feeny, S., \& Harris, M. N. (2007). Benchmarking firm performance. Benchmarking: An International Journal, 14(6), 693-710. http://dx.doi.org/10.1108/14635770710834491

Goncharuk, A. G., \& Monat, J. P. (2009). A synergistic performance management model conjoining benchmarking and motivation. Benchmarking: An International Journal, 16(6), 767-784. http://dx.doi.org/10.1108/14635770911000105

Jergeas, G. F. (2009). Improving Construction Productivity on Alberta Oil and Gas Capital Projects. Report to Alberta Finance and Enterprise project report, Alberta.

Lee, Y. P. (2006). Understanding factors for benchmarking adoption: New evidence from Malaysia. Benchmarking: An International Journal, 13(5), 548-565. http://dx.doi.org/10.1108/14635770610690401

Lincoln, Y. S., \& Guba, E. G (2000). Paradigmatic Controversies, Contradictions, and Emerging Confluences. In N. K. Dezin \& Y. S. Lincoln (Eds.), Handbook of Qualitative Research (2nd ed., pp. 163-188). Thousand Oaks, CA: Sage Publications Ltd in UK.

Mohamed, S. (1996). Benchmarking and improving construction productivity. Benchmarking for Quality Management \& Technology, 3(3), 50-58. http://dx.doi.org/10.1108/14635779610149151

Moriarty, J. P., \& Smallman, C. (2009). En route to a theory of benchmarking. Benchmarking: An International Journal, 16(4), 484-503. http://dx.doi.org/10.1108/14635770910972423

Nasir, H., Dorji, U., Attalla, M., Rankin, J., Fayek, A. R., \& Haas, C. (2008). Studies in Construction Performance Benchmarking. CSCE Annual Conference, June 10-13, 2008.1972. London.

Patton, M. Q. (1990). Qualitative Evaluation and Research Techniques (2nd ed.). Newbury Park, California: Sage Publication.

Rooke, J., Seymour, D., \& Crook, D. (1997). Preserving Methodological Consistency: A Reply to Raftery, McGeorge and Walters. Construction Management \& Economics, 15(5), 49. http://dx.doi.org/10.1080/014461997372845

Saunders, M. (2008). Implementing strategic initiatives: a framework of leading practices. International Journal of Operations \& Production Management, 28(11), 1095-1123. http://dx.doi.org/10.1108/01443570810910908 
Seymour, D., \& Rooke, J. (1995). The Culture of the Industry and the Culture of Research. Journal of Construction management and Economics, 13(6), 511. http://dx.doi.org/10.1080/01446199500000059

Walker, D. H. T. (1997). Choosing Appropriate Methodology. Journal of Construction Management and Economics, 15(2), 149. http://dx.doi.org/10.1080/01446199700000003

Williams, J., Brown, C., \& Springer, A. (2012). Overcoming benchmarking reluctance: a literature review. Benchmarking: An International Journal, 19(2), 255-276. http://dx.doi.org/10.1108/14635771211224563

\section{Copyright Disclaimer}

Copyright for this article is retained by the author(s), with first publication rights granted to the journal.

This is an open-access article distributed under the terms and conditions of the Creative Commons Attribution license (http://creativecommons.org/licenses/by/3.0/). 